\title{
A Method of Identification of Drilling Debris by Low Background Gamma Spectrum
}

\author{
Fan Chen ${ }^{1}$, Yang Jingke ${ }^{1}$, Lv Cangjin ${ }^{2}$
}

\author{
${ }^{1}$ College of Nuclear Technology \& Automation, Chengdu University of Technology, Chengdu 610059, China \\ ${ }^{2}$ The People's Hospital of Wenjiang, Chengdu 611133, China
}

\begin{abstract}
This paper provides a accurate method for dividing drilling debris. Firstly, K, Th and U counting rates of different drilling debris samples were measured by low background gamma spectrometer, and the relationship between sample quality and counting rate was obtained. Secondly, mudstone and limestone can be classified by the lithologic identification method. Finally, the specific lithology of mudstone can be divided by the relation of K, Th and $U$ counting rates. Experiments have shown the accuracy of lithological discrimination of drilling debris by this method is up to $80 \%$.
\end{abstract}

Keywords: Drilling Debris, Low Background Gamma Spectrometer, Lithologic Identify-Cation Method

\section{Introduction}

Gamma spectrometry is a fast and non-destructive method for measuring radionuclide activity in drilling debris. Radionuclides in drilling samples emit gamma rays when they decay. Quantitative and qualitative analysis of radionuclides is carried out by measuring gamma energy and irradiation rated ${ }^{[1]}$.

In this paper, the low background gamma spectrometer is used to measure drilling debris samples, find out the relationship between the characteristic parameters of gamma spectrometry and rock properties (lithology), and judge the rock properties of drilling debris based on the results of gamma spectrometry measurement ${ }^{[2]}$.

\section{Experiments}

\subsection{Measurement Principle}

The gamma ray irradiation produced by ${ }^{40} \mathrm{~K},{ }^{238} \mathrm{U}$ and

${ }^{232} \mathrm{Th}$ radiation source interacts with $\mathrm{NaI}(\mathrm{Tl})$ crystal.
The peak value of electric pulse is proportional to the energy of incident gamma ray, and the counting rate of electric pulse is proportional to the irradiation rate of incident gamma ray. After the electric pulse signal is formed by the preamplifier and linear pulse amplifier, it is input into the multi-channel pulse amplitude analyzer for signal acquisition and processing, and then the counting rate of gamma rays with different energy and the corresponding nuclide content are calculated. After calibration by standard source, the contents and counting rates of $\mathrm{K}, \mathrm{U}$ and $\mathrm{Th}$, as well as the total counting rate and total content can be directly output.

\subsection{Low Background Gamma Spectrum}

The low background gamma spectrometer is IED-3000B low background digital gamma spectrometer independently developed by Chengdu University of Technology. Its Circuit block diagram of main machine instrument is shown in Figure 1.

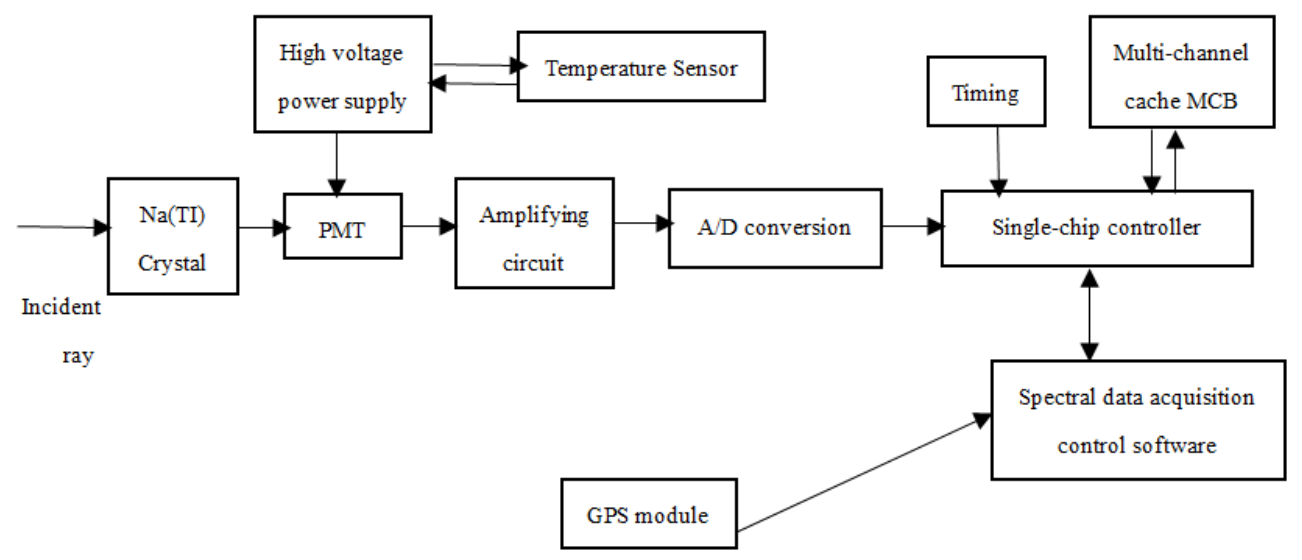

Fig. 1 Host circuit block diagram

This article is published under the terms of the Creative Commons Attribution License 4.0 Author(s) retain the copyright of this article. Publication rights with Alkhaer Publications. Published at: http://www.ijsciences.com/pub/issue/2019-07/

DOI: 10.18483/ijSci.2106; Online ISSN: 2305-3925; Print ISSN: 2410-4477 


\subsection{Low background lead chamber}

The low background lead chamber is designed to shield cosmic rays and gamma rays from external interference. A hollow cylinder with a wall thickness of $10 \mathrm{~cm}$ is used. Its outer diameter is $42 * 45 \mathrm{~cm}$ and its inner diameter is $20 * 22 \mathrm{~cm}$. The low background lead chamber is shown in Fig. 2.

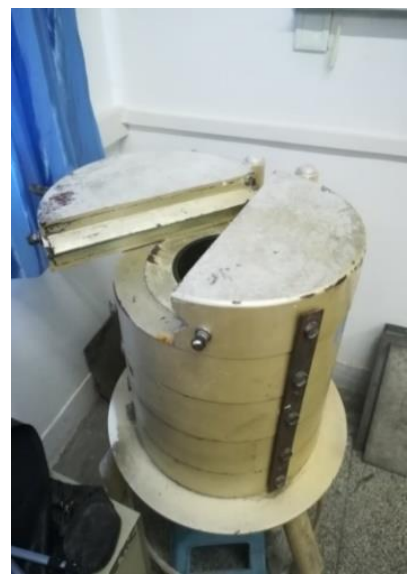

Fig.2 Low background lead chamber

\subsection{Sample preparation and measurement}

Thirty rock samples were selected from different depths and heights of borehole in an oil and gas exploration area. Each sample was weighed $200 \mathrm{~g}$ and ground by a grinding machine. The grinded samples were placed in a $100-110{ }^{\circ} \mathrm{C}$ oven for 2 hours to ensure the complete removal of moisture. The dried samples were packed and sealed in a cylindrical polyethylene plastic box and numbered. After reaching the radioactive balance, the measurement began. The measuring time was 3000 s.

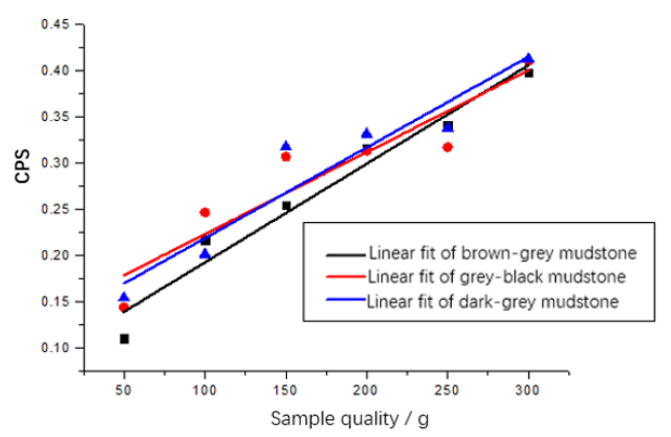

Fig.4 Relation between K-channel and sample quality

\section{Experimental results and discussions \\ 3.1 Selection of measuring energy zone}

The samples used in this paper are mainly drilling debris, which belong to mudstone and limestone in sedimentary rocks. The counting rates of $\mathrm{K}$, Th and $\mathrm{U}$ in the samples are mainly measured. Using $1.46 \mathrm{MeV}$ as ${ }^{40} \mathrm{~K}$ characteristic peak, $1.76 \mathrm{MeV}$ as ${ }^{238} \mathrm{U}$ characteristic peak and $2.62 \mathrm{MeV}$ as ${ }^{232} \mathrm{Th}$ characteristic peak, the counting rates of $\mathrm{K}$, Th and $\mathrm{U}$ were measured. The gamma-ray spectra of a rock sample measured by a $\mathrm{NaI}(\mathrm{Tl})$ detector are shown in Figure 3.

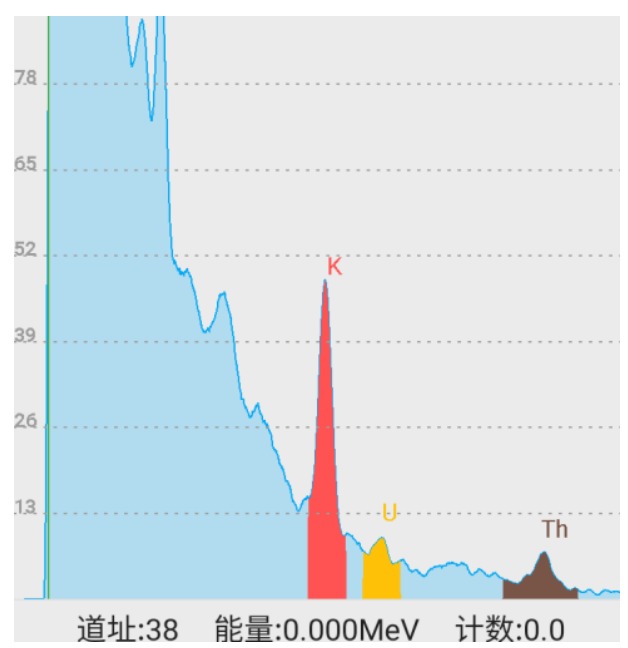

Fig.3 Gamma-ray spectrogram of measured drilling debris

\subsection{Sample quality measurement}

Three rock samples, brown-grey mudstone, grey-black mudstone and dark-grey mudstone, were measured six times with low background gamma-ray spectrometer, adding $50 \mathrm{~g}$ each time, totaling $300 \mathrm{~g}$. The counting rates of $\mathrm{K}$, Th and $\mathrm{U}$ channels and the total channel counting rates were recorded as shown in Figure 4-7.

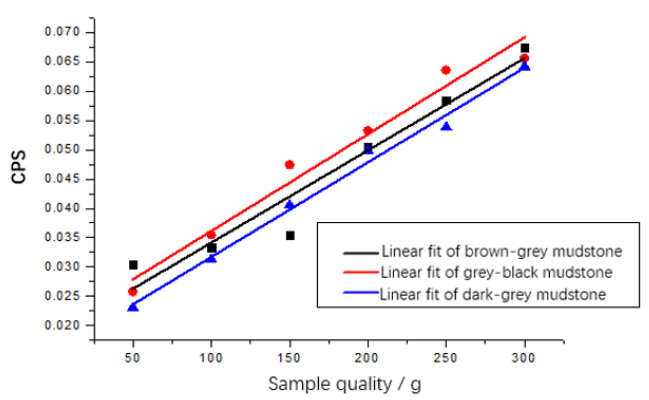

Fig.5 Th-channel and sample quality 


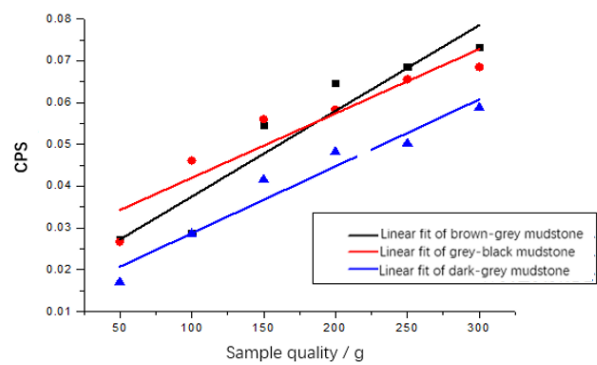

Fig.6 U-channel and sample quality

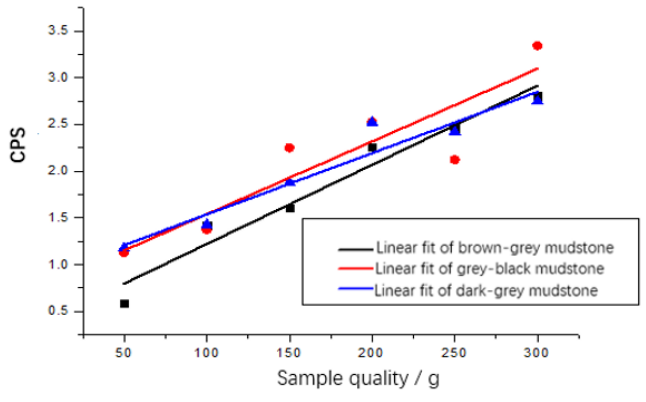

Fig.7 Total-channel and sample quality
With the increase of sample quality, the counting rates of $\mathrm{K}$, Th and $\mathrm{U}$ channels and the total channel counting rates increased linearly. In K-channel (Fig. 4), the linear coefficients of brown-gray mudstone and dark-gray mudstone are the largest and the same, and the grey-black mudstone is the smallest. In $\mathrm{U}$ channel (Fig. 5), the linear coefficients of lithology are the same. In Th channel (Fig. 6), the linear coefficient of brown grey mudstone is the largest, while that of grey black mudstone is the same as that of dark grey mudstone. The linear coefficients of brown grey mudstone and grey black grey mudstone are the largest and the same, while dark grey mudstone is the smallest.

\subsection{Lithology recognition method}

Lithology identification methods are established by using 20 known lithologic samples. According to the results of table 1 , mudstone and limestone are divided by total counting rate. The higher or lower total counting rate is limestone, and the mudstone is in the middle of the total counting rate. Grey-black grey mudstone can be identified from four kinds of mudstones by using $(\mathrm{K}+\mathrm{U}) / \mathrm{Th}$ value. Grey-black grey mudstone has the highest $(\mathrm{K}+\mathrm{U}) / \mathrm{Th}$ value. Then the brown-gray mudstone can be identified from the remaining three mudstones by $U+T h$ value. Finally, the remaining two kinds of mudstones are identified by $(\mathrm{K}+\mathrm{Th}) / \mathrm{U}$ value, and the relative error of $(\mathrm{K}+\mathrm{Th}) / \mathrm{U}$ value of two kinds of mudstones is more than $10 \%$. Therefore, dark grey limestone and grey limestone mudstone can be identified by $(\mathrm{K}+\mathrm{Th}) / \mathrm{U}$ value.

Tab1 Computational results

\begin{tabular}{cccccc}
\hline lithology & $\begin{array}{c}\text { total } \\
\text { number }\end{array}$ & total/cps & $(\mathrm{K}+\mathrm{U}) / \mathrm{Th}$ & $\mathrm{U}+\mathrm{Th}$ & $(\mathrm{K}+\mathrm{Th}) / \mathrm{U}$ \\
\hline Deep grey limestone mudstone & 10 & 5.952 & 6.904 & 0.088 & 7.526 \\
Grey limestone mudstone & 5 & 5.631 & 6.485 & 0.090 & 6.971 \\
Brown-grey argillaceous mudstone & 2 & 5.584 & 6.393 & 0.077 & - \\
Grey-black grey mudstone & 1 & 5.975 & 8.441 & - & - \\
Brown-grey cloudy argillaceous & 1 & 4.889 & - & - & - \\
limestone & 1 & 6.358 & - & - & - \\
Deep grey argillaceous limestone & 1 & & & - \\
\hline
\end{tabular}

\subsection{Method accuracy}

An additional 10 rock samples are used to test the accuracy of the discriminant method. The results of lithologic discriminant are shown in Table 2.

Tab2 Lithological discriminant results

\begin{tabular}{|c|c|c|c|c|c|c|c|}
\hline lithology & $\begin{array}{r}\text { well } \\
\text { depth }\end{array}$ & $\begin{array}{l}\text { Total } \\
\text { /cps }\end{array}$ & $(\mathrm{K}+\mathrm{U}) / \mathrm{Th}$ & $\mathrm{U}+\mathrm{Th}$ & $(\mathrm{K}+\mathrm{Th}) / \mathrm{U}$ & discriminant & results \\
\hline Deep grey limestone mudstone & 4004 & 5.660 & 6.415 & 0.087 & 8.068 & Deep grey limestone mudstone & exactness \\
\hline Deep grey limestone mudstone & 4005 & 5.979 & 6.908 & 0.080 & 8.292 & Deep grey limestone mudstone & exactness \\
\hline Deep grey limestone mudstone & 4007 & 5.814 & 7.416 & 0.091 & 7.762 & Deep grey limestone mudstone & exactness \\
\hline Deep grey limestone mudstone & 4008 & 5.761 & 6.405 & 0.100 & 6.692 & Grey limestone mudstone & incorrectness \\
\hline Deep grey limestone mudstone & 4015 & 5.892 & 7.110 & 0.095 & 7.234 & Deep grey limestone mudstone & exactness \\
\hline Deep grey limestone mudstone & 4016 & 6.105 & 6.934 & 0.107 & 5.907 & Grey limestone mudstone & incorrectness \\
\hline Deep grey limestone mudstone & 4017 & 5.816 & 7.042 & 0.084 & 8.137 & Deep grey limestone mudstone & exactness \\
\hline Deep grey limestone mudstone & 4018 & 6.065 & 5.445 & 0.094 & 9.160 & Deep grey limestone mudstone & exactness \\
\hline Deep grey limestone mudstone & 4021 & 5.978 & 6.320 & 0.091 & 8.886 & Deep grey limestone mudstone & exactness \\
\hline Deep grey limestone mudstone & 4023 & 5.606 & 5.548 & 0.090 & 8.344 & Deep grey limestone mudstone & exactness \\
\hline
\end{tabular}


It can be seen from the above table that 8 of the 10 lithologic samples can be correctly identified and 2 of the errors can be correctly identified by means of double mean square deviation test. So the accuracy of lithology identification by this method is up to $80 \%$.

\section{Conclusions}

In this paper, the debris samples are measured by low background gamma spectrometer. The total counting rate is used to divide mudstone and limestone. The lithology of mudstone can be distinguished by the relationship between $\mathrm{K}$, Th and $\mathrm{U}$ counting rates. The experimental results show that the $\mathrm{K}$, Th and $\mathrm{U}$ characteristic peaks are linearly related to the sample quality. This method can effectively divide the lithology of clastic rocks with an accuracy of $80 \%$.

\section{References}

1. Turhan,Lüfullah Gündüz.2008.Determination of specific activity of $226 \mathrm{Ra}, 232 \mathrm{Th}$ and $40 \mathrm{~K}$ for assessment of radiation hazards from Turkish pumice samples[J].Journal of Environmental Radioactivity, 99(2):332-342.

2. Moran B,Du Huynh,Edwards M.,et al.2008.On-belt analysis of minerals using naturally occurring gamma radiation[C]// IEEE International Conference on Acoustics. IEEE. 